\title{
Precision Profile Measurement System for Microholes Using Vibrating Optical Fiber
}

\author{
Takao Sajima*, Hiroshi Murakami ${ }^{1}$, Akio Katsuki, \\ Daisuke Tabuchi, Osamu Ohnishi, Syuhei Kurokawa, \\ Hiromichi Onikura and Toshiro K. Doi \\ Department of Mechanical Engineering, Faculty of Engineering, Kyushu University, \\ 744 Motooka, Nishi-ku, Fukuoka 819-0395, Japan \\ ${ }^{1}$ Department of Mechanical Engineering, Faculty of Engineering, Kyushu Sangyo University, \\ 2-3-1 Matsukadai, Higashi-ku, Fukuoka 813-8503, Japan
}

(Received June 10, 2011; accepted January 24, 2012)

Key words: profile measurement, fiber stylus, microhole, piezoelectric element

In this study, we have proposed and implemented a profile measurement system for microholes using an optical fiber probe equipped with a vibrating mechanism driven by a piezoelectric element. The optical fiber probe consists of a stylus shaft of $3 \mu \mathrm{m}$ diameter and a glass ball of $5 \mu \mathrm{m}$ diameter attached to the tip. The principle involves the monitoring of the stylus shaft displacement by detecting a change in the amount of light received by two dual-element photodiodes. These diodes are set up facing laser beams that are irradiated onto the shaft portion from the $\mathrm{X}$ and $\mathrm{Y}$ directions. In this study, a tube-type piezoelectric element was set at the base of the stylus allowing it to vibrate in the $\mathrm{X}$ and $\mathrm{Y}$ directions. Firstly, we examined the displacement detection characteristics and frequency response characteristics of the probe. Secondly, the performance of the vibrating mechanism was examined. Finally, the measurement performance of the fiber probe was experimentally examined by measuring a hole of $150 \mu \mathrm{m}$ diameter. The stylus could be operated in a circular path of $9.69 \mu \mathrm{m}$ diameter. The changes in amplitude and phase of vibration of the stylus allowed for contact detection with the hole wall. Our study has potential applications for measurements of microholes in the diameter range of $10-150 \mu \mathrm{m}$.

\section{Introduction}

In recent years, the measurement of the profiles of microholes has become a subject of considerable interest with the increase in the levels of precision in microfabrication

${ }^{*}$ Corresponding author: e-mail: sajima@mech.kyushu-u.ac.jp 
technologies. Technologies that can measure shapes with high aspect ratios (such as deep holes) are of particular importance. These holes can include various nozzle holes such as fuel injection nozzles or synthetic nozzles, and deep microholes such as ferrules and microchannels that are used in optical communication devices or medical equipment. Furthermore, the need for measuring the shapes and dimensions of microcomponents that comprise micromachines is increasing owing to recent advancements in these relevant technologies.

Various types of optical microscope have generally been used in the past to measure microholes. These measurements are generally obtained from the top position; the measurements include only the inlet section of a hole or the shapes of the inlet and outlet sections. Therefore, these microscopes cannot be used to evaluate the inside roundness, straightness, cylindricality, or surface roughness of a hole. Other techniques have included destructive inspections that involve the cross-cutting of a hole to measure the shapes inside the hole. The problem with destructive inspections is that once they are executed, the objects under such inspections can no longer be used. To guarantee the quality of the actual workpieces, nondestructive inspections are essential. To accurately measure a hole with a high aspect ratio by nondestructive inspection, a probe with a low measuring force, small diameter, and high aspect ratio is required.

Previous studies on microhole measurements for through-holes have reported optical methods involving the detection of reflected light at the hole outlet by shining light on the inner wall, ${ }^{(1)}$ laser-optical internal thread measurement, ${ }^{(2)}$ and those involving the triangulation method. ${ }^{(3)}$ Furthermore, other reported methods on blind hole measurements have included those involving a probe using the vibroscanning method, ${ }^{(4,5)}$ those based on an amplitude fluctuation due to the contact of a vibrating probe, ${ }^{(6-9)}$ the detection of the closeness of a probe and the surface of a measured object using the tunnel phenomenon, ${ }^{(10,11)}$ measurement of reflected light with a CCD image sensor by irradiating a laser beam on the ball tip of a probe, ${ }^{(12,13)}$ and measurement of probe distortion with a CCD image sensor. ${ }^{(14)}$ In addition, other reported blind hole measurement studies have involved techniques such as laser trapping contact elements using an optical fiber, ${ }^{(15)}$ the detection of the retention and contact of a contact element with air pressure, ${ }^{(16)}$ and the measurment of a diaphragm fixed on a probe with a displacement sensor. ${ }^{(17)}$

In this study, we propose a new optical fiber probe equipped with a vibrating mechanism driven by a piezoelectric element. The vibrating mechanism is introduced to prevent the adhesion of the stylus tip to the hole wall due to static electricity, surface tension of fluids, atomic forces, etc.; this adhesion decreases the measurement accuracy. Since the proposed probe takes a laser-based noncontact measurement of the displacement due to contact on the hole wall using a stylus tip, the probe shaft does not need to be rigid; this principle also applies when the diameter of the probe is made smaller. In this study, we first examine the displacement detection characteristics and frequency response characteristics of the probe. Secondly, we examine the vibrating mechanism to our satisfaction. Finally, the measurement performance of the fiber probe is experimentally examined by measuring a hole of $150 \mu \mathrm{m}$ diameter. 


\section{Measurement Principle}

A schematic of the optical fiber scope is shown in Fig. 1. A cross-sectional diagram for the X-Y plane of Fig. 1 is shown in Fig. 2 to indicate the measurement principle of the optical fiber probe. An optical fiber of $3 \mu \mathrm{m}$ diameter with a $5-\mu \mathrm{m}$-diameter stylus

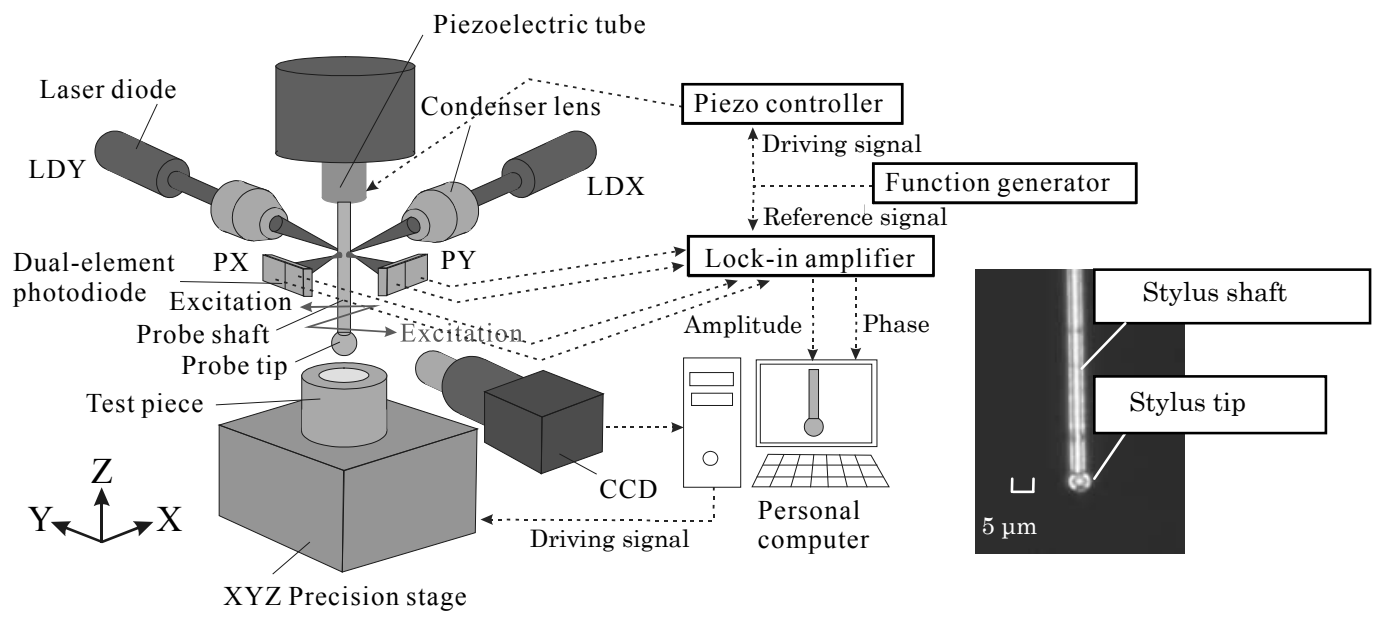

Fig. 1. Optical system of optical fiber probe.

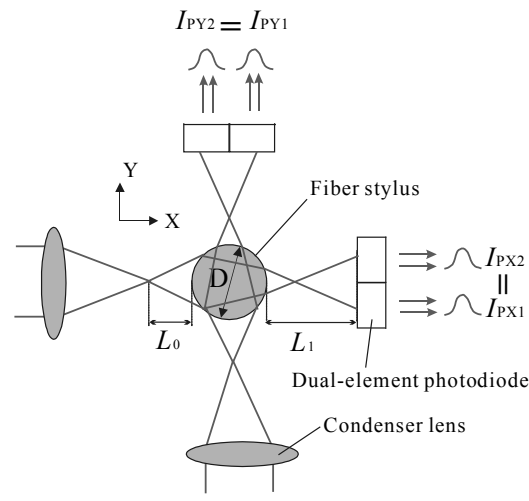

(a)

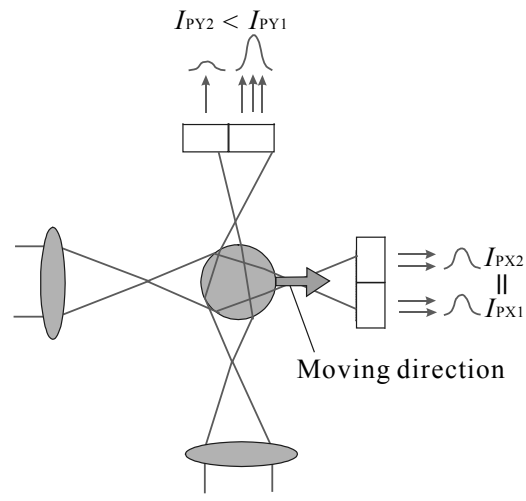

(b)

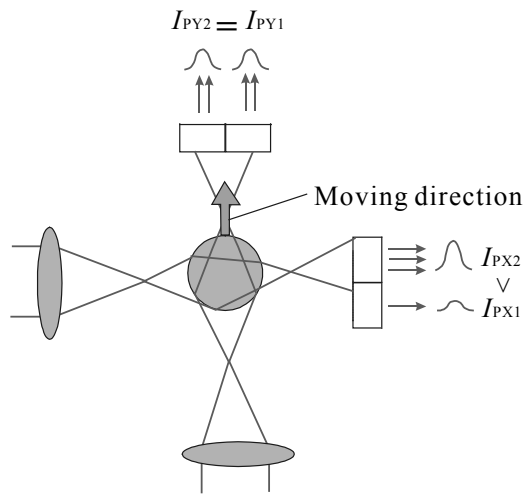

(c)

Fig. 2. Schematic diagram to explain the measurement principle. (a) Initial state, (b) displacement X, and (c) displacement Y. 
tip made of glass secured on the end (total length of $2 \mathrm{~mm}$ ) is used as a stylus. The stylus shaft is fixed onto a tube-type piezoelectric driver element used for producing vibrations. Furthermore, a semiconductor laser is mounted at a position $1 \mathrm{~mm}$ above the stylus tip to irradiate the focused laser beams along the $\mathrm{X}$ and $\mathrm{Y}$ directions onto the stylus shaft. The light that passes through the stylus shaft is received by two sets of dualelement photodiodes (PX and PY) that are fixed on the opposite sides of the laser beyond the stylus. The stylus shaft is used here as a rod lens to magnify the displacement of the stylus. The light intensity detected by the respective diodes is converted into voltage values referred to as $I_{\mathrm{PX} 1}, I_{\mathrm{PX} 2}, I_{\mathrm{PY} 1}$, and $I_{\mathrm{PY} 2}(\mathrm{~V})$.

The stylus is vibrated in a circular path using the tube-type piezoelectric element in the $\mathrm{X}$ and $\mathrm{Y}$ directions. When the stylus tip is not displaced, $I_{\mathrm{PX} 1}$ and $I_{\mathrm{PX} 2}$ as well as $I_{\mathrm{PY} 1}$ and $I_{\mathrm{PY} 2}$ are maintained at equal intensities. Once the stylus tip comes into contact with the surface of the measured object and the stylus shaft is displaced, a difference appears between the light intensities of $I_{\mathrm{PX} 1}$ and $I_{\mathrm{PX} 2}$ as well as $I_{\mathrm{PY} 1}$ and $I_{\mathrm{PY} 2}$, thereby making it possible to detect the direction of displacement of the stylus. For example, the initial condition depicted in Fig. 2(a) shows $I_{\mathrm{PX} 1}=I_{\mathrm{PX} 2}$ and $I_{\mathrm{PY} 1}=I_{\mathrm{PY} 2}$. However, once the stylus shaft is displaced along the $\mathrm{X}$ direction, as shown in Fig. 2(b), the resulting voltage conditions are $I_{\mathrm{PX} 1}=I_{\mathrm{PX} 2}$ and $I_{\mathrm{PY} 1}>I_{\mathrm{PY} 2}$. Furthermore, when the stylus shaft is displaced along the $\mathrm{Y}$ direction, as depicted in Fig. 2(c), the resulting conditions are given by $I_{\mathrm{PX} 1}$ $>I_{\mathrm{PX} 2}$ and $I_{\mathrm{PY} 1}=I_{\mathrm{PY} 2}$. The equations for output $I_{\mathrm{X}}(\mathrm{V})$ due to displacement along the $\mathrm{X}$ direction (using $I_{\mathrm{PY} 1}$ and $I_{\mathrm{PY} 2}$ ) as well as the output $I_{\mathrm{Y}}(\mathrm{V})$ along the Y direction (using $I_{\mathrm{PX} 1}$ and $I_{\mathrm{PX} 2}$ ) are shown as eqs. (1) and (2) below, respectively. The direction in which the stylus tip has contacted the measured surface as well as the amount of displacement can be obtained using outputs $I_{\mathrm{X}}$ and $I_{\mathrm{Y}}$.

$$
\begin{aligned}
& I_{\mathrm{X}}=I_{\mathrm{PY} 1}-I_{\mathrm{PY} 2} \\
& I_{\mathrm{Y}}=I_{\mathrm{PX} 1}-I_{\mathrm{PX} 2}
\end{aligned}
$$

The various noises involved in the outputs $I_{\mathrm{X}}$ and $I_{\mathrm{Y}}$ are removed by synchronous detection using a lock-in amplifier. Here, the signal of the function generator, which vibrates the stylus, is used as a reference signal. The contact of the stylus tip onto the measured surface is detected by monitoring the amount of change in the amplitude of vibration based on the output signal from the lock-in amplifier as well as the change in phases of output $I_{\mathrm{X}}$ and the reference signal.

\section{Probe Characteristics}

\subsection{Displacement detection characteristics}

Figure 3 shows the changes in outputs $I_{\mathrm{X}}$ and $I_{\mathrm{Y}}$ when the stylus tip is displaced along the $\pm \mathrm{X}$-axis direction. The amount of displacement of the stylus tip is represented on the horizontal axis, whereas the changes in outputs $I_{\mathrm{X}}$ and $I_{\mathrm{Y}}$ are represented on the vertical axis. When the stylus tip is displaced along the $\mathrm{X}$-axis direction, it can be verified that hardly any change has occurred in the output of $I_{\mathrm{Y}}$. Furthermore, the proportion of 


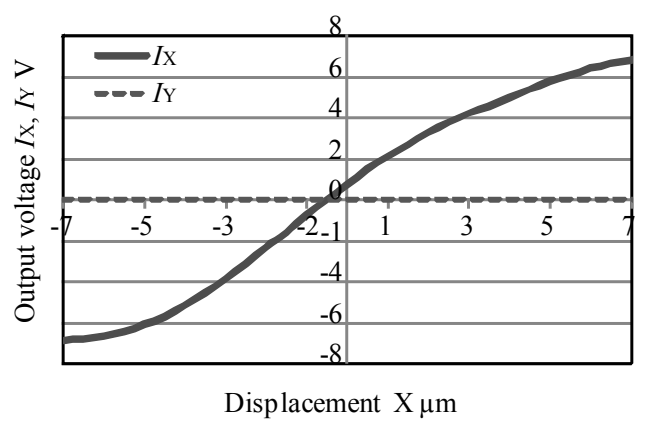

Fig. 3. Output voltages $I_{\mathrm{X}}$ and $I_{\mathrm{Y}}$ induced by X-displacement.

change in $I_{\mathrm{X}}$ can be verified to be practically approaching a straight line in the range of \pm $3 \mu \mathrm{m}$ in the $\mathrm{X}$-axis direction, as seen in the figure; therefore, the stylus can be effectively used as a displacement probe.

\subsection{Frequency response characteristics}

The resonance frequency can be derived from eq. (3) using the Bernoulli-Euler theoretical equation by assuming that the fiber probe is considered to be a cylindrical beam with a constant cross-sectional diameter and a cantilever that is fixed at one end and free at the other end with a concentrated mass (stylus tip), $m$. The details of the optical fiber used in the experiment are as follows: diameter of fiber $=3 \mu \mathrm{m}$, Young's modulus $E=72 \mathrm{GPa}$, diameter of stylus $=5 \mu \mathrm{m}$, and fiber length $=2 \mathrm{~mm}$.

$$
f=\frac{\lambda^{2}}{2 \pi} \sqrt{\frac{E I}{\rho A}}
$$

Here, $E$ represents the Young's modulus, $I$ denotes the geometrical moment of inertia, $A$ denotes the cross-sectional area, and $\rho$ denotes the density. Furthermore, $\lambda$ can be calculated using eq. (4), as derived under the boundary conditions of the abovementioned cantilever with a concentrated mass.

$$
b \cdot \lambda L=\frac{1+\cos \lambda L \cdot \cosh \lambda L}{\sin \lambda L \cdot \cosh \lambda L-\cos \lambda L \cdot \sin \lambda L}
$$

Here, $b$ denotes the mass ratio $(b=m / \rho A L)$ of the stylus tip and the optical fiber. The first-, second-, and third-order resonance frequencies calculated using eq. (3) are $f=600$, 3730 , and $10470 \mathrm{~Hz}$, respectively.

On the other hand, the amplitude of vibrational signals of $I_{\mathrm{X}}$ and $I_{\mathrm{Y}}$ became larger at $2000 \mathrm{~Hz}$ when the stylus was vibrated under those frequency regions using the tube-type 
piezoelectric element. The shape of the stylus was viewed under a microscope in order to find the resonance frequency difference in the calculation and experiment. As a result, it was observed that the diameter of the cylindrical stylus could not be uniformly reduced by etching in the machining process, and the shape of the stylus was found to be tapered. Under the condition that the diameter of the stylus is $7.4 \mu \mathrm{m}$ at a fixed end and $3 \mu \mathrm{m}$ at the joint with a mass to the other end, the resonance frequency was calculated using Finite Element Method (FEM) analysis. Hence, the first resonance frequency is 2000 $\mathrm{Hz}$, which corresponds to the experimental value of $2 \mathrm{kHz}$.

\section{Verification Experiment}

We performed a verification experiment for the abovementioned measurement principle using a block gauge. Figure 4 shows the schematic for this experiment. When the stylus tip contacts the surface of the measured object, the changes in the output were measured. Although the stylus was set to vibrate in a circular plane of motion of 9.69 $\mu \mathrm{m}$ diameter on the X-Y plane with a vibrational frequency of $2 \mathrm{kHz}$, the surface of the measured object was made to come in contact with the stylus tip along the X-axis. The measured surface was fixed on an XYZ stage and displaced with a $10 \mathrm{~nm}$ pitch along the $+\mathrm{X}$-axis. The amount of change in vibrational amplitude of output $I_{\mathrm{X}}$ in the $\mathrm{X}$-axis direction from the lock-in amplifier, as well as the phase between output $I_{\mathrm{X}}$ and the reference signal, is shown in Fig. 5. The amount of displacement of the measured surface is represented by the horizontal axis; the vertical axis represents both the change in amplitude due to vibration as well as the voltage for the amount of change in the phase. Significant changes in the amplitude due to vibration and phase occurred before and after contact, thereby verifying that it is possible to detect contact onto the measured surface using the principle described above.

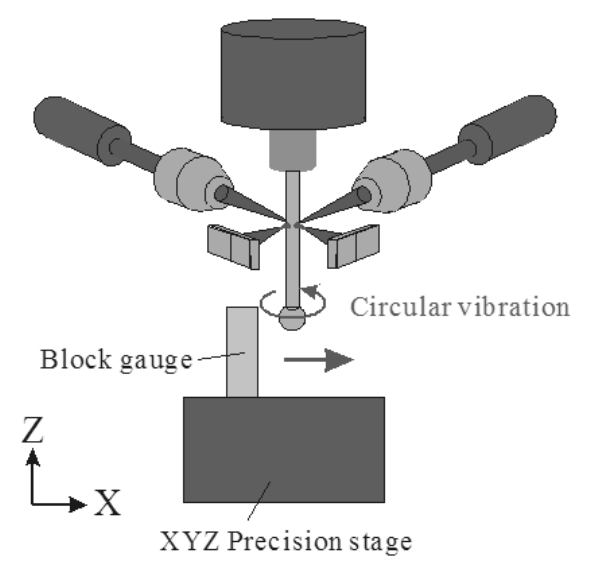

Fig. 4. Schematic for evaluating probe characteristics using a block gauge. 


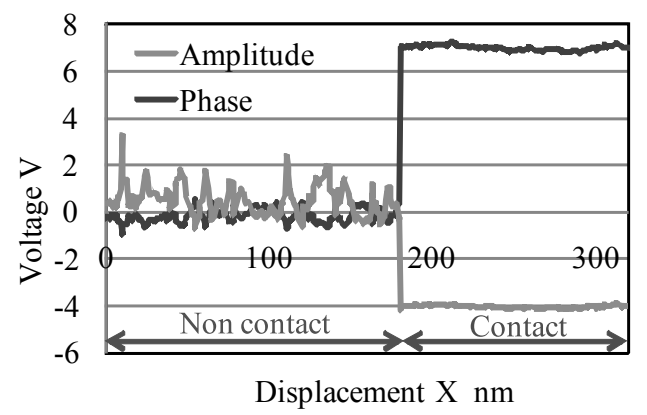

Fig. 5. Output voltage equivalent of amplitude and phase of stylus vibration induced by $\mathrm{X}$-displacement.

\section{Measurement of microhole}

The performance of the prototype measurement system is examined by measuring a microhole of $150 \mu \mathrm{m}$ diameter. Figure 6 shows the microhole.

The amplitude of the circular vibration of the stylus tip is calibrated using a block gauge of $1 \mathrm{~mm}$ width (Fig. 7). Firstly, the coordinates of both surfaces of the block gauge are measured by operating the probe with circular vibration. Subsequently, the distance between the two coordinates is calculated. Finally, the amplitude of circular vibration of the stylus tip can be obtained by subtracting the width of the block gauge from the distance of the two coordinates. The value obtained was $9.69 \mu \mathrm{m}$.

A schematic of the measurement method is shown in Fig. 8. The maximum hole depth (along the $\mathrm{Z}$ direction) for the measurement was approximately $100 \mu \mathrm{m}$. The hole was measured for every $15^{\circ}$ in the circumferential direction and every $25 \mu \mathrm{m}$ along the depth or $\mathrm{Z}$ direction. Figure 9 shows the measured roundness of the microhole. The maximum value of roundness was $6.02 \mu \mathrm{m}$. Figure 10 shows the measured hole profile. The hole diameter increased slightly with increasing depth along the $Z$ direction. The maximum hole diameter within the range of our measurement was $153.22 \mu \mathrm{m}$.

\section{Conclusions}

In our study, we proposed and implemented a prototype for a measurement system that uses a vibrating optical fiber for accurately measuring a microhole. In addition, we evaluated the performance of our measurement system. We were able to verify the following from the results.

1. A vibrating mechanism driven by a piezoelectric element can be operated in a circular motion within a diameter of $9.69 \mu \mathrm{m}$.

2. The contact of the stylus tip on the surface of a measured object can be detected by monitoring the amount of change in vibrational amplitude of output $I_{\mathrm{X}}$ in the X-axis direction from the lock-in amplifier as well as the change in phases of output $I_{\mathrm{X}}$ and the reference signal. 


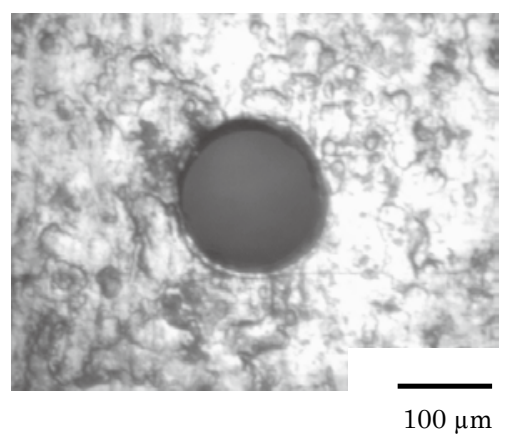

Fig. 6. Photograph of microhole.

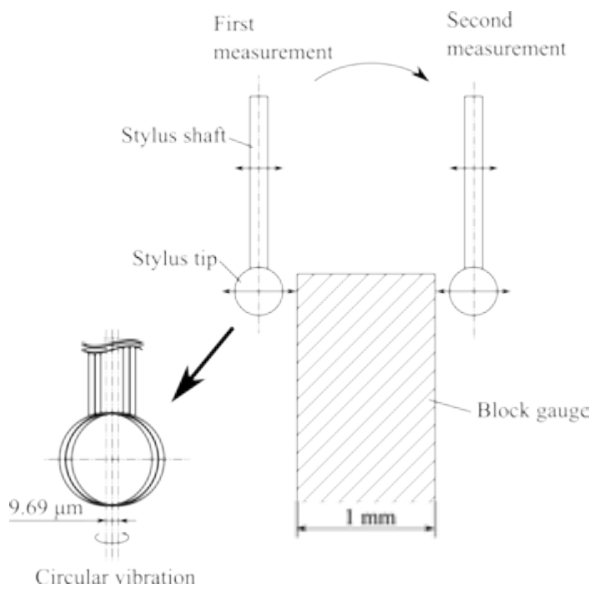

Fig. 7. Calibration of measurement probe.

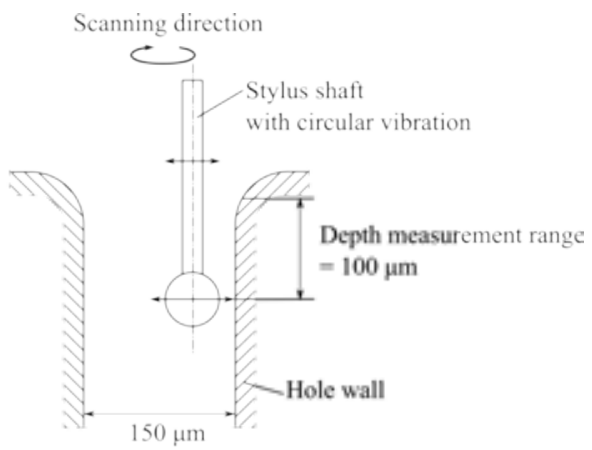

Fig. 8. Schematic of measurement method. 


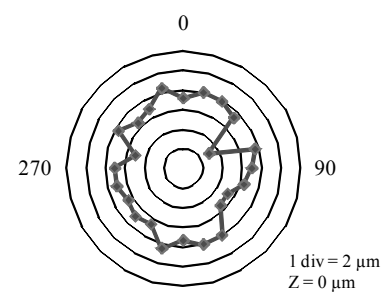

180

(a) $\mathrm{Z}=0 \mu \mathrm{m}$, Roundness $=5.45 \mu \mathrm{m}$

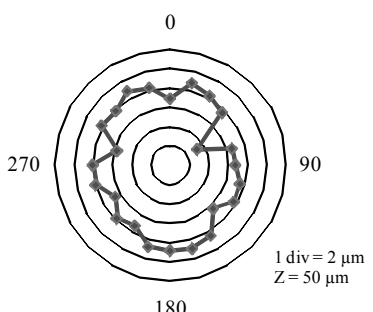

(c) $\mathrm{Z}=50 \mu \mathrm{m}$, Roundness $=5.69 \mu \mathrm{m}$

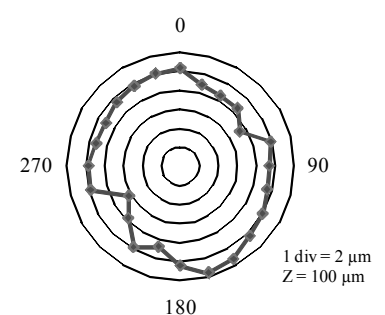

(e) $\mathrm{Z}=100 \mu \mathrm{m}$, Roundness $=5.35 \mu \mathrm{m}$

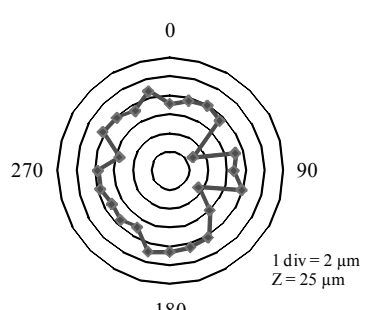

180

(b) $\mathrm{Z}=25 \mu \mathrm{m}$, Roundness $=6.02 \mu \mathrm{m}$

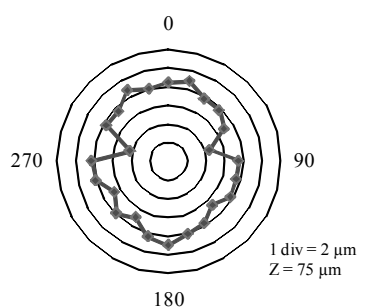

(d) $\mathrm{Z}=75 \mu \mathrm{m}$, Roundness $=4.77 \mu \mathrm{m}$

Fig. 9. Roundness (deviation from circularity) of the hole with the probe at each depth.

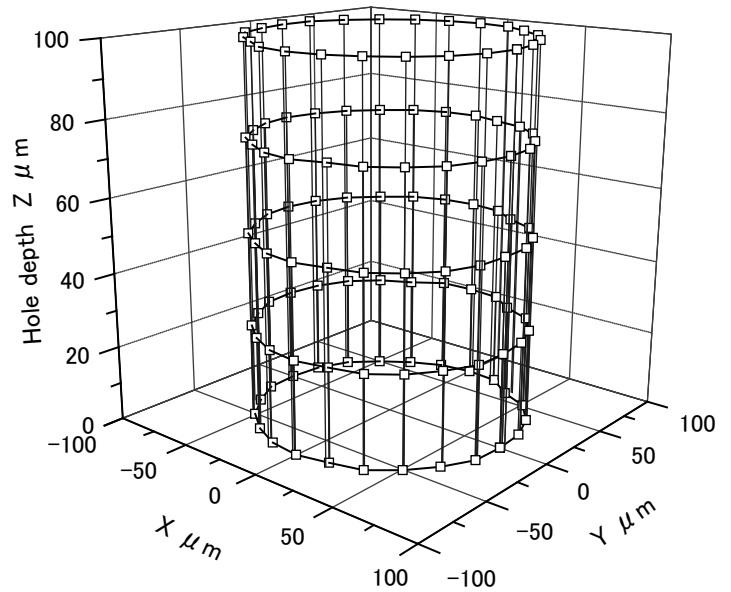

Fig. 10. Profile of $\phi 150 \mu \mathrm{m}$ microhole measured using measurement probe. 
3. The three-dimensional shape and roundness of microholes of $150 \mu \mathrm{m}$ diameter and $100 \mu \mathrm{m}$ depth can be measured using a prototype of a fiber probe. The maximum roundness in our measurement was $6.02 \mu \mathrm{m}$. The maximum hole diameter within the depth range of our measurement was $153.22 \mu \mathrm{m}$.

In our future studies, we plan to decrease the diameter of the circular motion of the piezoelectric element from 9.69 to $2 \mu \mathrm{m}$. Furthermore, we plan to implement our method of measuring the accuracy of a microhole with a diameter of less than $10 \mu \mathrm{m}$ using the probe.

\section{References}

1 M. Maruyama, H. Osaka, M. Ono and S. Kasei: J. Jpn. Soc. Precis. Eng. 62 (1996) 145 (in Japanese).

2 T. Pfeifer: CIRP Ann. 41 (1992) 577.

3 H. Onikura, Y. Kuwabara, T. Nakamura, T. Sajima, Y. Imazeki, A. Katsuki and S. Yamada: J. Jpn. Soc. Precis. Eng. 61 (1995) 248 (in Japanese).

4 T. Masuzawa, M. Hamasaki and M. Fujino: CIRP Ann. 42 (1993) 589.

5 T. Masuzawa, B. J. Kim, C. Bergaud and M. Fujino: CIRP Ann. 46 (1997) 437.

6 K. Hidaka and P. H. J. Schellekens: CIRP Ann. 55 (2006) 567.

7 K. Hidaka, H.-U. Danzebrink, H. Illers, A. Saito and N. Ishikawa: CIRP Ann. 59 (2010) 517.

8 K. Hidaka, A. Saito and S. Koga: CIRP Ann. 57 (2008) 489.

9 M. B. Bauza, R. J. Hocken, S. T. Smith and S. C. Woody: Rev. Sci. Instrum. 76 (2005) 095112.

10 T. Shiraishi and K. Mitsui: J. Jpn. Soc. Precis. Eng. 64 (1998) 1395 (in Japanese).

11 T. Shiramatsu, K. Kitano, M. Kawata and K. Mitsui: J. Jpn. Soc. Mech. Eng. Series C, 68 (2002) 267 (in Japanese).

12 H. Schwenke, F. Wäldele, C. Weiskrich and H. Kunzmann: CIRP Ann. 50 (2001) 361.

13 R. Thelen, J. Schulz, P. Meyer and V. Saile: Proc. 4th Int. Conf. on Multi-Material Micromanufacture 2008, p. 147.

14 B. Muralikrishnan, J. A. Stone and J. R. Stoup: Precis. Eng. 30 (2006) 154.

15 M. Michihata, Y. Takaya and T. Hayashi: CIRP Ann. 57 (2008) 493.

16 K. Takamasu, K. Kuo, A. Suzuki, M. Hiraki, R. Furutani and S. Ozono: Int. J. Jpn. Soc. Precis. Eng. 33 (1999) 233.

17 H. Haitjema, W. O. Pril and P. H. J. Schellekens: CIRP Ann. 50 (2001) 365. 